\title{
Erratum to: Arguing 'for' the Patient: Informed Consent and Strategic Maneuvering in Doctor-Patient Interaction
}

\author{
Peter J. Schulz ${ }^{1} \cdot$ Sara Rubinelli $^{1}$
}

Published online: 30 September 2015

(C) Springer Science+Business Media Dordrecht 2015

\begin{abstract}
As a way to advance integration between traditional readings of the medical encounter and argumentation theory, this article conceptualizes the doctorpatient interaction as a form of info-suasive dialogue. Firstly, the article explores the relevance of argumentation in the medical encounter in connection with the process of informed consent. Secondly, it discloses the risks inherent to a lack of reconciliation of the dialectical and rhetorical components in the delivery of the doctor's advice, as especially resulting from the less-than-ideal conditions of the internal states of the doctor and the patient, and the lack of symmetry in their status.
\end{abstract}

Keywords Medical encounter - Info-suasive dialogue · Informed consent · Strategic maneuvering · Pragma-dialectical rules of critical discussion

\section{Introduction}

The pragma-dialectical approach has a focus on what Tindale considers as typical of argumentation theories, namely that they "stress the underlying reasonableness of the activity and ways in which this should be achieved and maintained" (2006,

The online version of the original article can be found under doi:10.1007/s10503-008-9086-y.

It was brought to our attention that the paper "Arguing 'for' the Patient: Informed Consent and Strategic Maneuvering in Doctor-Patient Interaction," co-authored by Peter J. Schulz and Sara Rubinelli and published in Argumentation 22 (2008), pp. 423-432, has certain severe shortcomings in the references. For this reason, we have decided to ask the authors to prepare a new version of the paper in which these shortcomings have been remedied. The new version of the paper is published here-Frans H. van Eemeren, Editor-in-Chief.

Peter J. Schulz

peter.schulz@lu.unisi.ch

1 Institute of Communication \& Health, University of Lugano $(\mathrm{CH})$, Lugano, Switzerland 
p. 447). In past years, the Amsterdam school of argumentation has discussed one further aspect highlighted by Tindale, namely that, even in a context of reasonable discussion, arguers "may want to maintain that reasonableness on their own terms and achieve outcomes that are favourable to their own interests, and they will measure success in this way" (2006, p. 447). Or, as van Eemeren and Houtlosser put it (1999a, p. 164), while pragma-dialectical analysis "tended to concentrate on reconstructing primarily the dialectical aspects of argumentative discourse" (see also Tindale 2006, p. 448), a sound evaluation of argumentation requires an analysis "that reveals all aspects of the discourse pertinent to critical testing" (van Eemeren and Houtlosser 1999b, p. 479).

"In recognition of this, the development of the strategic maneuvering project is a welcome initiative that should bring argumentation theorists to take more seriously the rhetorical dimensions of argumentation" (Tindale 2006, p. 447).

Health-related issues can become in many respects topics for argumentative discourse and argumentative analysis: Whether the discussion focuses on ethical issues concerning organ donation, on whether or not euthanasia should be allowed, or on the argumentative moves that occur in advertising of medicines; these settings share many features interplaying rhetorical and dialectical strategies with other forms of debates on societal concerns.

In this paper, we intend to focus on argumentation in the field of the medical encounter. This field is not traditionally perceived as argumentative. Yet, as it will be shown later, it is particularly promising for advancing theoretical understanding of strategic maneuvering and can itself benefit, on an empirical ground, by adopting the pragma-dialectical analytical perspective.

Following an exploration of the literature on the medical encounter as a research field, we intend to illustrate the conditions that justify the use of argumentation, as well as to highlight the nature of certain specific argumentative moves that might cause particularly critical derailments of strategic maneuvering. As we shall show, the analysis will be centered around the concept of 'informed consent' and will help underline some constraints that are intrinsic to the doctor-patient interaction. A focus on these constraints will offer a basis for understanding how argumentation theory, more specifically pragma-dialectics, and health communication can mutually benefit from joining research perspectives on this topic.

\section{State of the Art}

In recent years, an increasing number of studies have examined interpersonal communication in doctor-patient consultation (Duggan 2006; Sarangi and Roberts 1999; Ong et al. 1995). As highlighted by Ong et al. (1995, p. 903), “descriptive and experimental research has tried to shed light on the communication process during medical consultation." Traditional (linguistic) approaches to the medical encounter are mainly designed within the field of discourse analysis and conversation analysis (Stubbs 1983; Atkinson and Heritage 1984; Heritage and Maynard 2006). Thus, communication has been analyzed by using different interaction analysis systems (IASs) that, in Ong et al.'s words (1995, p. 905), can be defined as “the methodic 
identification, categorization and quantification of salient features of the doctorpatient exchange." These systems are tailored according to clinical relevance, observation strategy, and channels of communicative behavior, i.e., instrumental (cure oriented) versus affective (care oriented) behavior. Two types of systems result from either the patient's need for cure and care when visiting a doctor: "the need to know and understand (cure) and the need to feel known and understood (care)" (Ong et al. 1995, p. 906).

Important IASs found in the literature include the Roter's IAS (RIAS), the Observer Checklist, the Observation System for Analyzing Interaction between doctors and patients, and the Patient-Centred Method for clinical situations (Roter et al. 1988; Roter and Frankel 1992; Ong et al. 1995). As Street (2003, p. 81) notes, following Waitzkin (1991), these forms of investigation "provide valuable insight into the complexities of discourse, the nuances of meaning, the human experience of health and the way in which social, political, and historical contexts impinge upon parts of the medical interaction." In the context of interpersonal communication, Street (2003, p. 64) distinguishes between two lines of enquiry: "One line of inquiry examines how patterns of provider-patient communication are related to the attributes of the patients (e.g. education, age, health status), the provider (e.g. gender and medical speciality) and their relationship (e.g. rapport and trust)" (see also Roter et al. 1988; Roter and Hall 1993; Thompson 1994; Ong et al. 1995; Street 2001). "A second line of research," Street (2003, p. 64) continues, "examines relationships between providers' and patients' communicative actions and the various outcomes resulting from the consultation (e.g. satisfaction with care, commitment to treatment and health improvement)" (see also Roter and Hall 1993; Stewart et al. 1999; Street 2001). According to Street (2003, p. 64) "these studies have identified sources of variability in the communicative content [...] of medical encounters." Yet they do little to explore the argumentative dynamics of the doctorpatient relationship.

The study of argumentation in health communication has started to receive some methodical attention from scholars of argumentation theory, but only in the design of intelligent healthcare systems, e.g., systems designed to interact directly with healthcare consumers, or with healthcare workers and caregivers with little training (Bickmore and Green 2006, preface). Within the domain of artificial intelligence (AI) approaches, argumentation is investigated as an instrument for changing health-related behaviors, tailoring explanations, advising patients on treatment regimes, and designing synthetic agents working in cooperation with the healthcare team (Bickmore and Green 2006; De Rosis et al. 2000; Grasso et al. 2000; Fox et al. 2001; Green 2005; Jenicek and Hitchcock 2005).

Outside the AI's domain, there are disparate streams of research which approach aspects of argumentation in the health setting. In particular, Walton (1985, p. xii) designed "idealized model of medical treatment and the deliberative process of the physician-patient relationship that arrives at decisions for treatment" (1985, p. xii). Here, the physician-patient interaction is analyzed as a "goal-oriented procedure" (Walton 1985, p. xiii), with a focus on "ethical questions concerning health-care policy, attitudes toward treatments and the medical profession" (synopsis of Walton 1985). However, the author considers certain concepts from argumentation theory 
such as the nature of the argument from expert opinion and the fallacy of many questions, as well as the Aristotelian concept of practical reasoning which presupposes argumentative patterns of self-interaction and self-deliberation. Brashers (1999, 2002), Brashers et al. (2000, 2006) explored the argumentative burdens of patients' self-advocacy and outlined some argument strategies for selfadvocacy such as establishing facts, obligation, and self-interests. Dickinson (1998) used a model of argumentation to make explicit the nature and function of data in decision-making. Upshur and Colak (2003) examined the role and use of evidencebased approaches to argue in favor of conclusions and recommendations.

Goodnight (2006) mentioned the utility of an argumentative approach for the criticism and development of the so-called practice of informed consent. As we believe, the concept of informed consent is of cardinal importance to understand the role and nature of argumentation in the medical encounter. In the following section, we thus illustrate our approach by building on the analysis started by Goodnight.

\section{The Medical Encounter as Info-suasive Dialogue}

The medical encounter is not traditionally perceived as argumentative (Rubinelli and Schulz 2006). The general idea is that this encounter is an instance of information-seeking dialogue. But this idea is only partially true.

The doctor-patient interaction is an information-seeking dialogue insofar as it starts from an initial situation in which one participant has some information that the other participant wants. Thus, to arrive at a diagnosis or prognosis, the doctor needs information from the patient which he gets through the anamnesis and the examination, while the patient needs information about his situation to understand what disease he has and what he has to do to improve his health or recover.

Having said this, however, the act of informing the patients is an instance of argumentation at a higher level. The doctor delivers information concerning the patient's physical status and treatments. But, while doing so, he also attempts to convince the patient that he has/does not have a certain specific conditionindividuated by the doctor following a certain pattern of reasoning — and, if he has it, that he has to follow a certain specific treatment—chosen by the doctor. In light of this, argumentation in the medical encounter can be best characterized as an instance of info-suasive dialogue, a dialogue blending information and persuasion in an inextricable manner.

To quote a couple of examples, when the doctor gives information about the benefits of a certain therapy, this information is not simply oriented at advancing the declarative/factual knowledge of the patient about the therapy. The doctor's emphasis on the benefits must convince the patient about the advantages of undertaking that therapy. In this sense, it is information on a therapy that aims to support the positive standpoint of the doctor about it. In a similar way, when the doctor discusses the side effects of a therapy that he would like the patient to start, the discussion is often oriented at minimizing the side effects in favor of the beneficial effects of the treatment as a way to support its appropriateness. 
The importance of considering the argumentative dimension of the doctorpatient interaction is nowadays particularly critical. In the past, argumentation in the medical encounter was a marginal characteristic of the interaction and resulted almost always in the doctor adopting an argumentative approach ex auctoritate that was, in the majority of cases, accepted by the patient. Nowadays, due to the progress of medicine-in primis the possibility of choosing among several treatments for the same disease - and to the amount of health-related information made available to the public by traditional and new media, patients are becoming more consumerist and inclined to claim power for themselves (Brashers et al. 2006). Without denying the expertise of the doctor, patients are now more involved in performances of selfadvocacy (Brashers 2002; Brashers et al. 2006) and less likely to be passive and to limit the expression of eventual doubts or disagreement with their doctors.

Moreover, this evolution of the medical encounter has in the last years been institutionalized by the process of informed consent where, on the one hand, the doctor has legal obligations to deliver certain information, and on the other hand, the patient - as the decision-maker-is in charge of its appraisal.

As rightly noted by Goodnight (2006), communication between the doctor and the patient is nowadays based on reasonable discussion. The doctor delivers information that becomes reasons for legitimizing his points of views, while the patient evaluates it and eventually acts upon it.

It should be clear from what has so far been underlined that, when compared to traditionally argumentative contexts such as that of a legal process, argumentation in the medical encounter arises from a rather different situation. A legal process ultimately starts from a discussion aimed at the resolution of a dispute about the acceptability of a claim. Argumentation becomes an essential instrument to defend the claim and to decide whether the claim itself is acceptable (Feteris 1999).

The medical encounter does not start from an initial conflict between the doctor and the patient. Most patients go to see their doctors essentially to ask for advice, and they normally lack an a priori attitude to argue with their doctors and cast doubts on their standpoints. Argumentative exchanges occur there as resulting from differences of opinion concerning specific aspects of the consultation, i.e., when the patient doubts or disagrees with the doctor's advice at the level of prognosis or, moreover, of treatment and when the doctor conveys specific standpoints that could be questioned or in any case are to be exposed to evaluation by the patient. Speaking about the doctor, more specifically, we have shown elsewhere (Schulz and Rubinelli 2006) that he performs four main argumentative action-types. He uses argumentation to:

- justify a diagnosis

- justify a treatment or the need of additional investigation

- correct patients' wrong declarative or procedural knowledge

- minimize patients' concerns (we speak in this case of "emotive argumentation"). 


\section{Informed Consent and Strategic Maneuvering}

We now intend to address a general issue that seems to emerge when reflecting on the concept of strategic maneuvering in the medical encounter, and that must be taken into consideration for further more specific analysis of the individual argumentative moves that occur in this form of interaction. Providing that strategic maneuvering is involved in every move made in argumentative discourse, in the medical encounter, the balance between the dialectical and rhetorical aims of the doctors can be affected at all levels of the interaction by a tension instantiated by the process of informed consent. To explain this in more detail, we first highlight some of the essential features of informed consent.

Informed consent is a legal doctrine that has been elaborated by the courts over a number of years. It requires that doctors, before administering medical treatments, elicit the voluntary consent of patients. For this purpose, they are bound to disclose to patients all relevant information about illnesses and treatment options (Doyal 2000). Far from being a purely informative act, informed consent is a form of deliberative argumentation where dialectical and rhetorical features come to interplay (Goodnight 2006). Informed consent involves that a patient agrees on a certain treatment upon a full appreciation and understanding of the facts and implications of an action. The doctor must furnish all information needed to put the patient in the position to choose freely whether or not undertaking a certain treatment. He must explain the nature of his suggestion, as well as the reasonable alternatives to the proposed intervention and the risks, benefits, and uncertainties related to each alternative. The communication of all this information is part of the obligation of the doctor who must-for legal reasons-confirm to the requirement of informed consent (Doyal 2000).

As just anticipated, the communication of information that is relevant for informed consent involves a clear rhetorical dimension. Indeed, if it is true that the doctor is legally bound to present options equally, as a matter of fact he privileges the treatment he is proposing. This double dimension creates instances of strategic maneuvering directed at diminishing this tension between the claimed data-driven objectivity of the medical advice and the authority of the doctor who, as the expert, has reasons for considering a certain treatment to be more appropriate than the others.

That the doctor frankly admits and supports his biases is portrayed in the literature as a positive factor: It is "a better protector of the patient's right to autonomous choice than artificial neutrality would be" (Quill and Brody 1996, p. 765). However, whenever getting the patient to accept these biases is the exclusive goal of the doctor, then strategic maneuvering fails and argumentation becomes less instrumental toward informed consent as this is legally and institutionally conceived.

There are several constraints in the doctor-patient relationship that might be an obstacle to the conduct of a critical discussion and favor the dominance of rhetorical components in the doctor-patient interaction. And when rhetorical components 
prevail, the risk is that the patient does not receive enough fair and balanced information for reflecting on the doctor's advice.

In adopting the informed consent dimension, it is clear that the doctor's goal of convincing the patient of his standpoint's acceptability should not prevail over his obligation to deliver certain specific content and should not affect the way these contents are indeed delivered. For this purpose, the doctor-who wants to conform to the idea of "informed consent"-has to maneuver the argumentation strategically, i.e., he has to support his standpoint while, at the same time, conforming to the rules for critical discussion.

How strategic maneuvering occurs in real practice is an empirical question that we plan to explore in future work. What must be discussed here is the existence in the medical encounter of certain constraints that become evident when considering the role of the patient as co-arguer or evaluator of the doctor advice. They are constraints that could impact on the way argumentation between the doctor and the patient develops, by preventing the patient from either engaging in a discussion that could be constructive toward decision-making or adequately calibrating and responding to derailments of the norms of critical discussion excessive by the doctor.

According to pragma-dialectics, a resolution-oriented discussion implies a code of conduct presuming that both parties interact toward agreement. This code of conduct is articulated in first high-order conditions, designed to resolve any constraint that prevents resolution of potential disagreement, as well as in secondorder conditions oriented to the presupposed attitudes and intentions of the arguer (van Eemeren et al. 1993).

Among the first-order conditions, Commandment 1 claims that "discussants may not prevent each other from advancing standpoints or from calling standpoints into question" (van Eemeren and Grootendorst 2004, p. 190). Here we find a first constraint.

As already noted, in the medical encounter, differently from other context such as the legal one, there is no clear conflict of opinion in the confrontation stage. Patients may lack appropriate expertise to cast doubts or may be perceived to lack the appropriate expertise to engage at the level of co-arguer. Providing expertise to empower them up to the point where they can have peer-to-peer interactions with their doctor is an unrealistic idealization. An important analytical question that arises from here is how the patient and, moreover, the doctor deal with this difference of expertise in their respective argumentative moves.

Similarly, Commandment 2 claims that "discussants who advance a standpoint may not refute to defend this standpoint when requested to do so" (van Eemeren and Grootendorst 2004, p. 191). The verification of this condition in the medical encounter is difficult. From the doctor point of view, it may well be the case that the clinical reasons behind a certain advice are too technical to be made explicit. From the patient point of view, it is often the case that the patient does not have an argumentation in support of his standpoint. Patients often report second opinions or information that they have heard or read elsewhere and generally lack the ability to contextualize this information so as to discuss about it in a sufficiently framed way. It is true that referring to a second opinion puts the burden of proof back on the 
doctor's side. But lack of time can lead the doctor to ignore the burden and leave the patient himself to deal with eventual other opinions.

Commandment 8 claims that "standpoints may not be regarded as conclusively defended by argumentation that is not presented as based on formally conclusive reasoning if the defence does not take place by means of appropriate argument schemes that are applied correctly" (van Eemeren and Grootendorst 2004, p. 194). The verification of this condition is also problematic insofar as it is not clear what an appropriate argument scheme in this context is. According to pragma-dialectics, argument schemes are appropriate if both parties in the discussion agree on their use (van Eemeren and Grootendorst 1992). In discussing the medical setting, however, some normative concerns are needed. Indeed, the acceptability of an argument scheme by the parties is important in the perspective of resolving a difference of opinions between the doctor and the patient, but not in the perspective of enhancing informed consent. Thus, for example, the argument from authority-which may be fallacious in several context-is an argument scheme much utilized by doctors and which finds its foundation and legality in the expertise of the doctor comparing to that of the patient. But when thinking about informed consent, an argument ex authority is not the best way to inform patients on the reasons behind a certain treatment advanced. On the other side of the coin, an argument based on a causal argumentation-where a standpoint is defended "by making a causal connection between the argument and the standpoint" (van Eemeren et al. 2002, p. 100)—is definitely an appropriate argument scheme for enhancing informed understanding of why a certain treatment is advised. Yet, given the asymmetry in the technical knowledge of the doctor and the patient, such a scheme might communicate information that the patient does not understand.

A last constraint-which is more at the level of second-order conditionconcerns the interest of the doctor compared to that of the patient. Doctors nowadays prioritize the diagnosis. Indeed, as Schulz (2006, p. 109) explains: "while diagnosis refers to a present instant of time, the prognosis is considered to be a statement that refers to the likely outcome of a patient's disease." As a statement about the future, "prognosis entails a greater degree of uncertainty than a statement about the present" (Schulz 2006, p. 110). Thus, Schulz (2006, p. 111) continues: "the medical assessment of a disease embraces empirically describable and fixable parameters such as blood pressure, cholesterol level, number of leukocytes, just to mention a few." In this light, a disease technically conceived results in an aggregate of diagnostic findings.

When looking at patients, Schulz (2006, pp. 111-112) explains: "the most important question concerns their own future and what kind of physical disturbances they may have to take into account. And it is due to some initial disturbance of his well-being that the patient is usually consulting a doctor in order to gain some respite. Therefore, beside its functional disturbance, the concept of a disease refers to a state of a missing well-being and, as such, to a subjective state of being."

Clearly, this different orientation creates mismatches at the level of the opening stage of any argumentative exchange, when it is a matter of finding out how much relevant common ground they share and of underlining a "zone of agreement" sufficiently broad to conduct a fruitful discussion (van Eemeren and Grootendorst 2004). 


\section{Argumentation Versus Health Communication and Back Again}

In conclusion, we would like to make some remarks on what we consider as the main analytical promising links between argumentation theory-more specifically pragma-dialectics - and health communication.

Pragma-dialectics can enrich traditional approaches to doctor-patient interaction. Firstly, it offers conceptual tools for bringing into light aspects of this interaction that so far have not been explored. Secondly, as a resolution-oriented theory of argumentation, pragma-dialectics provides a normative model of critical conduct toward discussion-resolution that can result in the identification of good practices of doctor-patient argumentative exchange. This model offers a rich analytical and evaluative basis for understanding when argumentation between the doctor and the patient occurs and in what forms, how the doctor maneuvers strategically (i.e., he balances reasonableness and rhetorical goal) and when, however, he diverges from a critical discussion, potentially obstructing the interaction leading to informed consent.

In its turn, the exploitation of the validity of pragma-dialectics in the medical encounter can foster its theoretical developments. In particular, verifying how strategic maneuvering develops in a field that so far has not been explored in these terms will test and stretch the adaptability of pragma-dialectical conceptual standards, and first and foremost of those rules of reasonableness which are cardinal for the evaluation of a critical discussion. Pragma-dialectics will find of interest to look for reasonable interaction in a field where the "psychological makeup" of the arguers (van Eemerent et al. 1993, p. 32), e.g., the internal states of arguers and symmetry in their status, is definitely less than ideal.

Acknowledgments We wish to thank Bart Garssen for his acute remarks on the earlier version of this paper.

\section{References}

Atkinson, J., and J. Heritage. 1984. Structure of social action. Studies in conversation analysis. Cambridge: Cambridge University Press.

Bickmore, T., and N. Green (eds.). 2006. Argumentation for consumers of healthcare. Papers from the 2006 AAAI Spring Symposium, Stanford University. Menlo Park, CA: AAAI Press.

Brashers, D.H. 1999. The patient self-advocacy scale (PSAS): Measuring involvement in health care decision making. Health Communication 11: 97-122.

Brashers, D.H. 2002. Satisfying the argumentative requirements of self advocacy. In Advances in pragma-dialectics, ed. F.H. van Eemeren, 291-308. Newport News, VA: Vale Press.

Brashers, D.H., S. Haas, R. Klingle, and J. Neidig. 2000. Collective AIDS activism and individual's perceived self-advocacy in physician-patient communication. Human Communication Research 26 : 372-402.

Brashers, D.H., L.S. Rintamaki, E. Hsieh, and J. Peterson. 2006. Pragma-dialectics and self-advocacy in physician-patient interactions. In Considering pragma-dialectics, ed. P. Houtlosser, and A. van Rees, 23-34. Mahwah, NJ: Lawrence Erlbaum Associates.

de Rosis, F., F. Grasso, C. Castelfranchi, and I. Poggi. 2000. Modelling conflict-resolution dialogues. In Computational conflicts, ed. H. Müller, and R. Dieng, 41-62. Berlin: Springer.

Dickinson, H. 1998. Evidence-based decision-making: An argumentative approach. International Journal of Medical Informatics 51: 71-81. 
Doyal, L.T. (ed.). 2000. Informed consent in medical research. London: BMJ Publications.

Duggan, A. 2006. Understanding interpersonal communication processes across health contexts: Advances in the last decade and challenges for the next decade. Journal of Health Communication 11: 93-108.

Feteris, E. 1999. Fundamentals of legal argumentation. Dordrecht: Kluwer.

Fox, J., D. Glasspool, and J. Bury. 2001. Quantitative and qualitative approaches to reasoning under uncertainty in medical decision making. In Proceedings of the 8th conference on artificial intelligence in medicine in Europe (AIME), ed. S. Quaglini, P. Barahona, and S. Andreasson, 272-282. Berlin: Springer.

Goodnight, G.T. 2006. When reasons matter most: Pragma-dialectics and the problem of informed consent. In Considering pragma-dialectics, ed. P. Houtlosser, and A. van Rees, 75-85. Mahwah, NJ: Lawrence Erlbaum Associates.

Grasso, A., A. Cawsey, and R. Jones. 2000. Dialectical argumentation to solve conflicts in advice giving. A case study in the promotion of healthy nutrition. International Journal of Human-Computer Studies 53: 1077-1115.

Green, N. 2005. A Bayesian network coding scheme for annotating biomedical information presented to genetic counseling clients. Journal of Biomedical Informatics 38: 130-144.

Heritage, J., and D. Maynard. 2006. Communication in medical care: Interactions between primary care physicians and patients. Cambridge: Cambridge University Press.

Jenicek, M., and D. Hitchcock. 2005. Logic and critical thinking in medicine. Chicago, IL: AMA Press.

Ong, L., J. de Haes, A. Hoos, and F. Lammes. 1995. Doctor-patient communication: A review of the literature. Social Science and Medicine 40: 903-918.

Quill, T., and H. Brody. 1996. Physician recommendations and patient autonomy. Finding a balance between physician power and patient choice. Annals of Internal Medicine 125: 736-769.

Roter, D.L., and R. Frankel. 1992. Quantitative and qualitative approaches to the evaluation of the medical dialogue. Social Science and Medicine 34: 1097-1103.

Roter, D., and J. Hall. 1993. Doctors talking to patients/patients talking to doctors: Improving communication in medical visits. Westport, CT: Auburn House.

Roter, D., J. Hall, and N. Katz. 1988. Patient-physician communication: A descriptive summary of the literature. Patient Education and Counseling 12: 99-119.

Rubinelli, S., and P.J. Schulz. 2006. Let me tell you why! When argumentation in doctor-patient interaction makes a difference. Argumentation 20: 353-357.

Sarangi, S., and C. Roberts. 1999. Talk, work and institutional order: Discourse in medical, mediation and management settings. Berlin: Mouton de Gruyter.

Schulz, P.J. 2006. The communication of diagnostic information by doctors to patients in the consultation. In Bordering biomedicine, ed. V. Kalitzkus, and P.L. Twohig, 103-118. Amsterdam: Rodopi.

Schulz, P.J., and S. Rubinelli. 2006. Healthy arguments for literacy in health. In Report of the American Association for Artificial Intelligence (AAAI): Spring symposium on argumentation for consumer of healthcare, 86-95. Stanford: AAAI Press.

Stewart, M., J. Brown, J. Boon, L. Galajda, L. Meredith, and M. Sangster. 1999. Evidence on patientdoctor communication. Cancer Prevention and Control 3: 25-30.

Street, R. 2001. Active patients as powerful communicators. In The new handbook of language and social psychology, ed. W. Robinson, and H. Giles, 541-560. Chichester: Wiley.

Street, R. 2003. Communication in medical encounters: An ecological perspective. In Handbook of health communication, ed. T.L. Thompson, et al., 63-94. Mahwah, NJ: Lawrence Erlbaum.

Stubbs, M. 1983. Discourse analysis. The sociolinguistic analysis of natural language. Oxford: Basil Blackwell.

Thompson, T. 1994. Interpersonal communication and health care. In Handbook of interpersonal communication, ed. M. Knapp, and G. Miller, 696-725. Thousand Oaks, CA: Sage.

Tindale, C.V. 2006. Constrained maneuvering: Rhetoric as a rational enterprise. Argumentation 20: 447-466.

Upshur, R., and E. Colak. 2003. Argumentation and evidence. Theoretical Medicine and Bioethics 24: 283-299.

van Eemeren, F.H., and R. Grootendorst. 1992. Argumentation, communication, and fallacies. A pragmadialectical perspective. Hillsdale, NJ: Lawrence Erlbaum Associates.

van Eemeren, F.H., and R. Grootendorst. 2004. A systematic theory of argumentation. Cambridge: Cambridge University Press. 
van Eemeren, F.H., R. Grootendorst, S. Jackson, and S. Jacobs. 1993. Reconstructing argumentative discourse. Tuscaloosa, AL: The University of Alabama Press.

van Eemeren, F.H., R. Grootendorst, and A.F. Snoeck Henkemans. 2002. Argumentation. Analysis, evaluation, presentation. Mahwah, NJ: Lawrence Erlbaum Associates.

van Eemeren, F.H., and P. Houtlosser. 1999a. Delivering the goods in a critical discussion. In Proceedings of the fourth conference of the International Society for the Study of argumentation, ed. F.H. Eemeren, A.J. Blair, Ch. Willard, and B. Garssen, 163-168. Amsterdam: Sic Sat.

van Eemeren, F.H., and P. Houtlosser. 1999b. Strategic maneuvering in argumentative discourse. Discourse Studies 1: 479-497.

Waitzkin, H. 1991. The politics of medical encounters. New Haven, CT: Yale University Press.

Walton, D.N. 1985. Physician-patient decision making: A study in medical ethics. Westport, CT: Greenwood Press. 